\title{
Complex size-dependent habitat associations in potamodromous fish species
}

\author{
José Maria Santos $\cdot$ Luís Reino $\cdot$ Miguel Porto $\cdot$ João Oliveira $\cdot$ \\ Paulo Pinheiro $\cdot$ Pedro Raposo Almeida $\cdot$ Rui Cortes $\cdot$ Maria Teresa Ferreira
}

Received: 9 August 2010/Accepted: 26 October 2010/Published online: 10 November 2010

(C) Springer Basel AG 2010

\begin{abstract}
Knowledge of the distribution of species life stages at multiple spatial scales is fundamental to both a proper assessment of species management and conservation programmes and the ability to predict the consequences of human disturbances for river systems. The habitat requirements of three native cyprinid species-the Iberian barbel Barbus bocagei Steindachner, the Iberian straight-mouth nase Pseudochondrostoma polylepis (Steindachner), and the Northern straight-mouth nase Pseudochondrostoma duriense (Coelho)—were examined at 174 undisturbed or minimally disturbed sites in 8 river catchments across western Iberia, by modelling occurrence and counts of species life stages at two spatial scaleslarge (regional) and instream (local)—using hurdle models.
\end{abstract}

J. M. Santos $(\varangle) \cdot$ L. Reino · P. Pinheiro · M. T. Ferreira $\mathrm{CEF}$, Centro de Estudos Florestais, Instituto Superior de Agronomia, Universidade Técnica de Lisboa, 1349-017 Lisbon, Portugal

e-mail: jmsantos@isa.utl.pt

L. Reino

CIBIO, Centro de Investigação em Biodiversidade e Recursos Genéticos, Universidade do Porto, Campus Agrário de Vairão, 4485-661 Vairão, Portugal

L. Reino

ERENA-Ordenamento e Gestão de Recursos Naturais,

Rua Robalo Gouveia 1-1A, 1900-392 Lisbon, Portugal

L. Reino

Cátedra "Rui Nabeiro"-Biodiversidade, CIBIO,

Universidade de Évora, 7004-516 Évora, Portugal

M. Porto

Departamento de Biologia Vegetal, CBA,

Centro de Biologia Ambiental, Faculdade de Ciências de Lisboa,

Universidade de Lisboa, C2 Campo Grande,

1749-016 Lisbon, Portugal
All the life stages of the barbel showed a negative association with upstream high-gradient river reaches, whereas juvenile $P$. duriense favoured such areas. Stream width and openness were negatively related with the occurrence of juvenile and small adult barbel, but not with large adults. Juvenile nase, on the other hand, were found to be mainly confined to fast-flowing habitats with high instream cover and coarser substrata. Advanced life stages of the barbel were mainly associated with the "pure" regional and shared components, whereas the purely local attributes accounted for much of the model variation among nases, in particular juveniles, and juvenile barbel. The results of this study are useful for setting or refining management goals, and highlight the need to separately consider life stages

J. Oliveira $\cdot$ R. Cortes

CITAB, Centro de Investigação e de Tecnologias

Agro-Ambientais e Biológicas, Universidade de Trás-os-Montes

e Alto Douro, Quinta de Prados, 5001-801 Vila Real, Portugal

P. Pinheiro

AQUALOGUS-Engenharia e Ambiente,

Rua da Tóbis Portuguesa, n. ${ }^{\circ}$ 8-Escritório 3,

1750-292 Lisbon, Portugal

P. R. Almeida

Departamento de Biologia, Universidade de Évora,

7002-554 Évora, Portugal

P. R. Almeida

Instituto de Oceanografia, Faculdade de Ciências de Lisboa,

Universidade de Lisboa, Campo Grande,

1749-016 Lisbon, Portugal 
when performing conservation-related studies of species distribution.

Keywords Life stage - Regional/local environment . PCA · Hurdle models · Variation partitioning · Cyprinids

\section{Introduction}

Knowledge of species distribution at multiple spatial scales is crucial to both the management and conservation of aquatic biodiversity and the ability to assess the consequences of anthropogenic changes in the river environment, such as damming and climate change (Root and Schneider 1995). Until recently, fisheries ecologists have attempted to help managers with the task of conserving fish populations by conducting research — primarily at small spatial scalesthat focuses on describing species responses to local environmental conditions and is often only weakly linked to the larger-scale problems these managers are asked to address (Allan 2004). Such studies are often targeted at a single river or a specific region, and thus cannot be generalized to cover broader spatial scales (Lammert and Allan 1999). Streams are hierarchical systems in which large-scale climatic, geological and topographical factors determine the context of geomorphic processes (e.g. hydrology, sediment transport, woody debris recruitment) that create and maintain habitats at smaller local scales (Frissell et al. 1986). Modelling the occurrence and counts of fish species should therefore also account for the influence of large-scale regional factors that condition species presence within drainage basins (Huston 1999).

Several studies have examined the relationships between environmental factors and biological data at different spatial scales, particularly from a regional versus local sitebased perspective (e.g., Reino et al. 2006; Ferreira et al. 2007a). When results obtained from both approaches are compared, such studies have very often come to conflicting conclusions about the nature of specific ecological systems (e.g. Wiley et al. 1997). This view of the system at very different scales often pays more attention to a number of different types of functional mechanism (e.g. abiotic and biotic) that structure populations, and what is more, may require distinct statistical techniques, thereby leading to divergent hypotheses and conclusions (Root and Schneider 1995). Because species are subjected to processes that operate at both the landscape (regional) and instream (local) habitat scales (Allan et al. 1997), there is a need to better understand their relative importance and assess the spatial scale at which changes in the landscape should be evaluated for their impact on species populations.

Advances in the field of landscape ecology placed a new emphasis on the importance of habitat heterogeneity by introducing the concept of a dynamic landscape model of fish life history (Schlosser 1991, 1995). This model highlights the spatial arrangement of habitats for the different fish life stages and the key role that movement between them plays in complete species life cycles. More recently, riverine landscapes have been recognized as "riverscapes"-a series of complex mosaics of habitat types and environmental gradients in which fishes' movements play a pivotal role in fulfilling their life cycles (Fausch et al. 2002). Fish life stages require different physical habitats, and their complete life cycles may extend over large spatial scales, depending on the life-history characteristics of each species (Schlosser 1995). It is thus clear that models which describe the influence of landscape attributes on fish populations need to integrate the effect of multiple landscape attributes-i.e. regional and local—on the different life stages of fish. This is of major importance in the case of potamodromous species, which typically move a great deal within freshwater river systems (Lucas and Baras 2001). However, while a lot of information is available for commercial and game species, like salmonids, little is known about the ecology of potamodromous Iberian speciesnamely their habitat requirements at multiple spatial scales. Moreover, such information has often displayed contradictory results. For example, in terms of habitat guild based on the level of rheophily, the literature has classified the potamodromous Iberian cyprinid species Iberian barbel Barbus bocagei Steindachner as either rheophilic (Ferreira et al. 2007b), limnophilic (Oliveira 2006), or eurytopic (Lobón-Cerviá and Fernandez-Delgado 1984). Such findings raise the question of whether habitat requirements should be determined for the species, as reported in most studies (e.g. Pont et al. 2005; Mesquita et al. 2006), or if attention should instead be focused on analysing sizerelated (i.e. ontogenetic) differences in habitat use patterns and related instream habitat partitioning. This is particularly important for potamodromous species, given that different life stages are likely to exhibit different habitat requirements, with these habitat-use patterns being mediated by migratory processes (Northcote 1978). Quantifying the relationships between life stages of potamodromous species and environmental gradients measured at multiple spatial scales will improve knowledge of the mechanisms that influence species occurrence and counts, and will help conserve and manage their populations.

The use of different modelling techniques to understand the role of environmental gradients in species abundance has been recognised as a crucial step in conservation and/or restoration frameworks (Olden and Jackson 2002). However, whether they look at presence/absence or counts, most of these studies often exhibit a large proportion of zero values, (i.e. are said to be "zero-inflated") and/or show evidence of overdispersion (e.g. Potts and Elith 
2006), and therefore do not fit standard distributions (e.g. normal, Poisson, and binomial) for which they are routinely modelled. On the other hand, this zero inflation can be derived from the presence of an excess number of "true zero" observations, i.e. caused by unsuitable habitat or environmental processes, or can also be the result of sampling or observer errors during data collection ("falsezero" observations). Failing to account both for the presence of excess zero observations as well as their respective source will cause bias in parameter estimates and may lead to invalid scientific inferences (Martin et al. 2005). Though models that deal with zero inflation have mainly been used in disciplines such as medicine, healthcare, and econometrics, there has recently been an upsurge of interest in such techniques in the fields of ecology and animal science (e.g. Podlich et al. 2002; Potts and Elith 2006).

The present study investigates the environmental correlates at two spatial scales (i.e. regional and local) of three native potamodromous Iberian cyprinid fishes - the Iberian barbel Barbus bocagei Steindachner, the Iberian straightmouth nase Pseudochondrostoma polylepis (Steindachner) and the Northern straight-mouth nase Pseudochondrostoma duriense (Coelho)—which are partitioned by life stages in Western Iberia using hurdle models. Analyses also focus on how multi-scale influences interplay to shape the distribution of species life stages. Finally, results are used to discuss potential applications in the management of habitat and species populations.

\section{Materials and methods}

Study area

The study area has been described in detail elsewhere (Santos et al. 2006; Ferreira et al. 2007a). Briefly, the study was conducted in the eight largest river catchments in central and northern Portugal. The geology is complex and includes granites, schists and quartzites with various degrees of metamorphism, mainly in the inland area; whereas the western coast is dominated by tertiary layers under quaternary deposits; and the southern region, below the main course of the river Tagus, by the flat platforms of the Hesperic Massif. The climate is variable and reflects both the elevation and the proximity of the Atlantic Ocean, ranging from temperate oceanic on the northern border of the study area, to Mediterranean pluviseasonal in the continental and southern regions. The river discharge presents a high intra-annual variability, with high floods occurring in autumn and early winter, followed by a gradual decline towards late spring and summer, when most of the streams, particularly in the southernmost regions, turn into a series of isolated pools or even dry out completely. Land-use varies greatly across the study area: the northern and central part is mostly forested with Pinus and Eucalyptus plantations, and also presents a patchy pattern of orchards, vineyards, olive groves and irrigation crops; southern areas are more homogenous and are characterised by the presence of cork-oak and holm-oak woodlands.

Site collection

Sample sites were extracted in advance from a dataset of more than 500 sampling locations right across the country (Ferreira et al. 2007a). Only undisturbed or minimally disturbed sites were considered. The identification followed the EU-FAME project approach (Melcher et al. 2007; Pont et al. 2007), in which human disturbance is ranked semi-quantitatively using all available field data and GIS information. In the present case five disturbance variables were considered: connectivity of the river segment, hydrological regime, morphological condition, input of toxic and acidic effluents, and nutrient organic input. Each variable was scored from 1 (minimum disturbance) to 5 (maximum disturbance), and only sites scoring 1 or 2 for all five variables were retained for analysis. In addition, only sites spaced out $2 \mathrm{~km}$ from each other were retained for analyses to reduce problems of spatial autocorrelation while maintaining a sufficiently large sample size. This yielded a total of 174 sites from eight river catchments (Minho, Lima, Cávado, Douro, Vouga, Mondego, Lis, and Tagus) in western Iberia (northern and central Portugal) (Fig. 1).

\section{Fish sampling}

Sampling was conducted during late spring-summer baseflow conditions (May-July) in order to prevent reproductive migration periods (March-April, Santos et al. 2005) and extreme-flow events from causing bias in fish sampling or in the measurement of local habitat variables. Sites were electrofished (DC, 300-700 V, or pulsed DC, 400-1,000 V, SAREL model WFC7-HV, Electracatch International, Wolverhampton, UK) with single passes according to CEN (2003) standards, to encompass multiple habitat types (riffles, pools). The sampled distance was at least 20 times the mean wetted width of the channel. The entire widths of wadeable streams were fished by walking slowly upstream and using one anode for every $5 \mathrm{~m}$ of stream width. Rivers with mean depths exceeding $0.6 \mathrm{~m}$ were electrofished by boat moving downstream, again sampling all habitat types, but focusing on the margins. Capture efficiency estimates, assumed to be constant across sites, were not available for the area but previous studies indicated that this sampling effort was sufficient to capture a large range of fish sizes (Ferreira et al. 2007a), though it 
Fig. 1 Map of the study area and location of the 174 sampling sites in the different river basins across Portugal

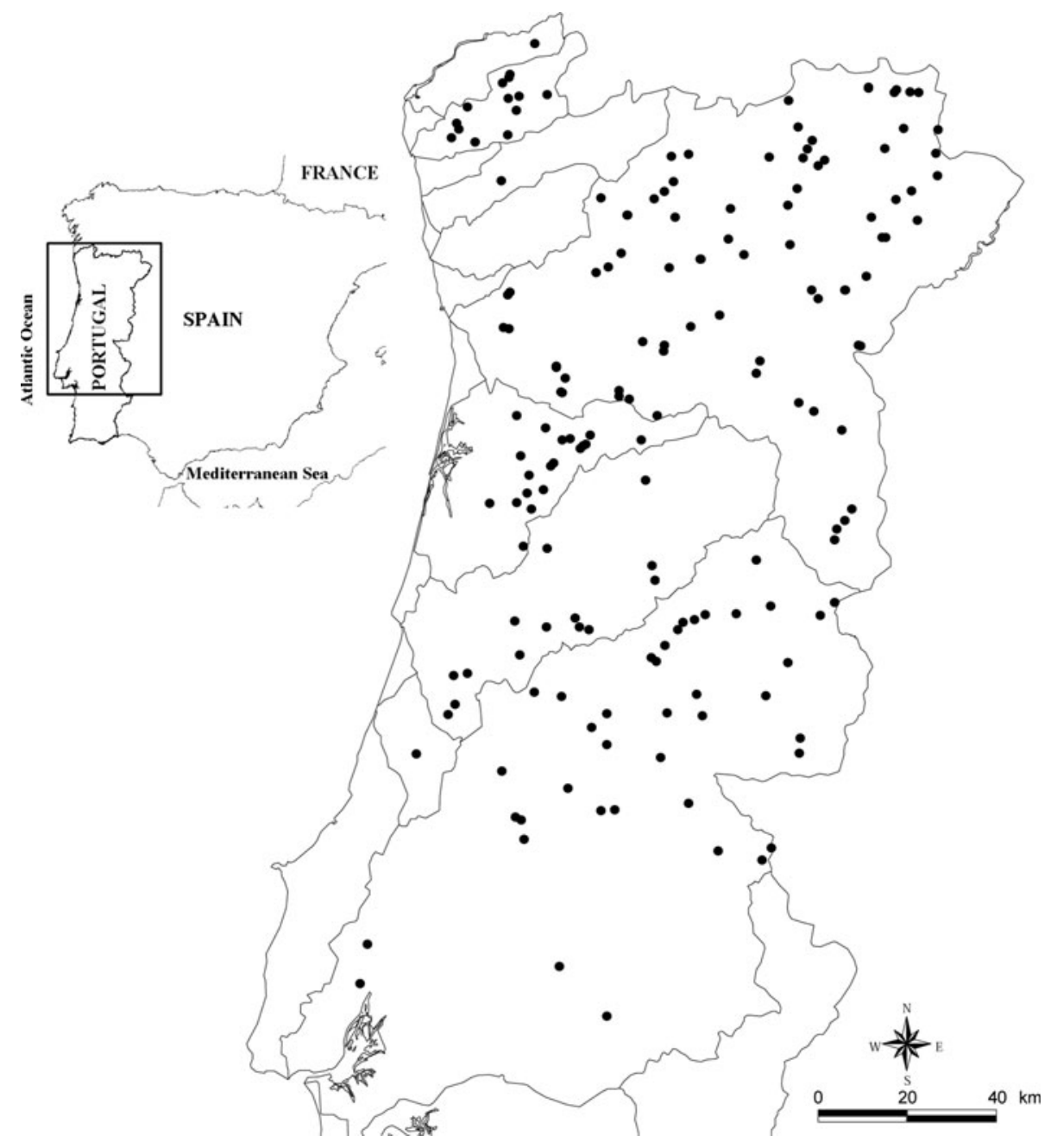

did not catch larvae and small young-of-the-year, for which specific protocols are needed (Copp 1989). After the sampling, fishes were identified, counted, measured (total length, $L_{\mathrm{T}}$, to the nearest $1.0 \mathrm{~mm}$ ), and returned to the river alive. To account for ontogenetic differences in species counts, fishes were stratified into distinct size-classes according to reported differences in age, growth, and reproduction (Lobón-Cerviá 1982; Lobón-Cerviá and Fernandez-Delgado 1984; Doadrio 2001), although such divisions are somewhat arbitrary and flexible depending on catchment characteristics (Oliveira et al. 2002): $\leq 10$ (juveniles), 10-20 (small adults) and $\geq 20 \mathrm{~cm} L_{\mathrm{T}}$ (large adults) for barbel; and $\leq 11,>11 \mathrm{~cm} L_{\mathrm{T}}$ for nase, which roughly correspond to the juvenile and adult life stages, respectively. Counts of species lifestages was reported as total number of individuals per ha.

\section{Environmental variables}

The analyses of factors associated with species occurrence and counts focused on two sets of environmental variables that reflect the regional context and local habitat attributes (Table 1). Regional variables included catchment area $\left(\mathrm{km}^{2}\right)$, distance from source $(\mathrm{km})$, altitude $(\mathrm{m})$, gradient slope $(\%)$, mean air temperature $\left({ }^{\circ} \mathrm{C}\right)$, mean annual rainfall $(\mathrm{mm})$, average annual runoff $(\mathrm{mm})$, and water mineralization [scored as 1 (low) to 3 (high)]. Catchment area, distance from source, altitude, and gradient slope were derived from digital elevation models. Mean air temperature and mean annual rainfall were determined from climate models based on time series between 1941 and 1942, and 1990 and 1991, from Portuguese weather stations. Average annual runoff $(1=<25 \mathrm{~mm} ; 2=25-50$ $\mathrm{mm} ; 3=50-100 \mathrm{~mm} ; 4=100-150 \mathrm{~mm} ; 5=150-200$ $\mathrm{mm} ; \quad 6=200-300 \mathrm{~mm} ; \quad 7=300-400 \mathrm{~mm} ; \quad 8=400$ $600 \mathrm{~mm} ; 9=600-800 \mathrm{~mm} ; 10=800-1000 \mathrm{~mm} ; 11=$ $1000-1400 \mathrm{~mm} ; 12=1400-1800 \mathrm{~mm} ; 13=1800-2200$ $\mathrm{mm} ; 14=>2200 \mathrm{~mm})$ and water mineralization $(1=$ low; $2=$ medium; $3=$ high) were obtained from cartographic sources (Agência Portuguesa do Ambiente 2007). Local variables included mean wetted width $(\mathrm{m})$, mean depth (m), water velocity, dominant substrate coarseness, 
instream cover, shading, and hydrological regime at the site. Width was recorded from five transects, regularly spaced across the channel. Depth was measured with a graduated dip-net pole along each transect at a number of random points (mean number $=25$ ). Water velocity was measured using a calibrated dip-net in randomly selected points along the transects and was quantified using three ordinal categories (Santos et al. 2006): 1, no flow (no movement of the net); 2, weak flow (slow ballooning of the net); and 3, faster flow (moderate to fast ballooning of the net). Dominant substrate coarseness $(1=$ silt, $<2 \mathrm{~mm}$ particle size; $2=$ sand, $<5 \mathrm{~mm}$ particle size; $3=$ gravel/pebble/cobble, $<150 \mathrm{~mm}$ particle size, and $4=$ boulder/rock, $>150 \mathrm{~mm}$ particle size) and cover (defined as (a) logs or any submerged structure (other than substrate) in which fish could be hidden from overhead view and (b) undercut banks, submerged or overhanging vegetation $<50 \mathrm{~cm}$ above water surface) were determined visually in $0.8 \times 0.8 \mathrm{~m}$ quadrats below each point. Cover was scored as: 0, absent; 1, some $(<25 \%)$; dense (25-60\%); and heavy $(>60 \%)$ cover. Overhanging tree shading (visually determined as $0=$ absent; $1:<25 \% ; 2$ : $25-60 \%$ and $3:>60 \%)$ and hydrological regime ( 0 -summer drying; 1-permanent) were also determined for each sampling site.

Table 1 Mean/median and range of environmental variables measured at 174 sites in western Iberia

\begin{tabular}{llc}
\hline & Mean/median & Range \\
\hline Regional variables & & \\
Catchment area $\left(\mathrm{km}^{2}\right)$ & $404.23( \pm 48.33)$ & $10.23-3262.35$ \\
Distance from source $(\mathrm{km})$ & $38.41( \pm 2.50)$ & $6.90-151.39$ \\
Altitude $(\mathrm{m})$ & $280.36( \pm 15.09)$ & $6.00-880.00$ \\
Gradient slope $(\%)$ & $6.61( \pm 0.66)$ & $0.01-17.90$ \\
Mean air temperature $\left({ }^{\circ} \mathrm{C}\right)$ & $13.45( \pm 0.13)$ & $9.89-15.56$ \\
Mean annual rainfall $(\mathrm{mm})$ & $1008.13( \pm 33.14)$ & $485.00-2208.00$ \\
Average annual runoff $(\mathrm{class})$ & $6(4)$ & \\
Mineralisation (class) & $1(1)$ & \\
Local variables & & \\
Mean depth (m) & $0.57( \pm 0.03)$ & \\
Mean width (m) & $11.80( \pm 0.77)-2.00$ \\
Water velocity (class) & $2(1)$ & \\
Substrate coarseness (class) & $3(1)$ & $2(1)$ \\
Shade (class) & $2(1)$ & $1(0)$
\end{tabular}

Mean values are given for continuous variables followed by standard error (in parentheses), while median values (with interquartile distance in parentheses) are given for discrete (categorical) variables See "Materials and methods (environmental variables)" for description of classes from categorical variables
Statistical analyses

Principal component analyses (PCA) of $z$-score normalized environmental variables (Ostrand and Wilde 2002) were first performed for each species' natural area of occurrence (B. bocagei: all river catchments; $P$. duriense: Douro, Cávado, Lima, and Minho catchments; P. polylepis: Tagus, Lis, Mondego, and Vouga catchments), to extract both regional and local gradients. A varimax rotation was applied to the set of principal components with eigenvalues $>1$, in order to obtain simpler and more interpretable environmental gradients (Legendre and Legendre 1998). Loadings $\geq 10.70 \mid$ were used for the interpretation of environmental gradients.

A preliminary visual inspection of the histograms of the frequency of counts for the target species revealed data to be zero-inflated (Fig. 2). Species occurrence and counts were modelled using hurdle models, as the extent in terms of the number of sites and sampled area suggests that zero observations are predominantly true zeros (Tyre et al. 2003). The hurdle model (Cragg 1971) consists of two parts. The first is typically a binary (presence/absence) response model (e.g. a logistic regression), while the second is usually a truncated-at-zero count model (see detailed model equations in Potts and Elith (2006)). The hurdle model is therefore a modified count model in which the separate processes generating the zeroes and positive counts are not constrained to be the same. This methodology allows the interpretation of the positive outcomes $(>0)$ that result from passing the zero hurdle (threshold). Overall, these models recognise the possibility that the mechanisms which determine presence can be different to those which determine abundance (Ridout et al. 1998).

Fish life stage responses to regional and local environmental gradients extracted from PCA were estimated using hurdle models, thereby accounting for the presence of zeroinflation. Logistic regression was used to model the binary (presence/absence) component, whereas the negative binomial (NB) distribution modelled the positive counts. Hurdle NB models have been shown to be particularly suitable for modelling data characterized by an excess of zeroes (Welsh et al. 2000). The association between the explanatory variables and the response variable was tested separately for both the regional and local environmental gradients, and subsequently using only the significant ones to produce the final model. First, a set of a priori candidate "partial" models was selected that included all possible combinations of environmental gradients. Given the relatively limited dataset, only linear responses were evaluated in order to avoid the development of overly complex models. The hurdle model approach was then implemented using the number of fish recorded at a site as the dependent variable and the sets of explanatory environmental 

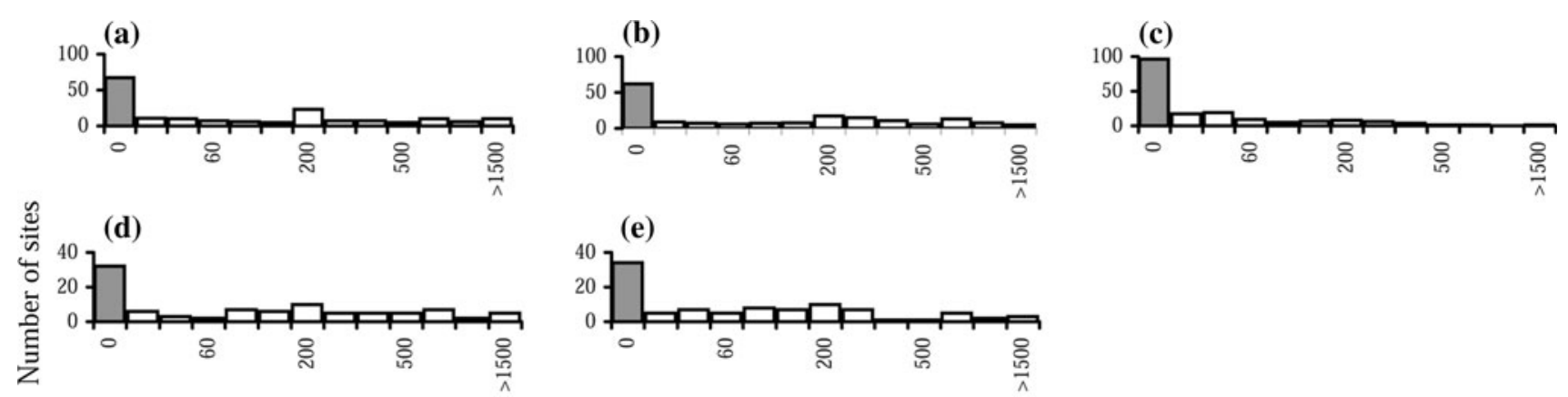

(e)
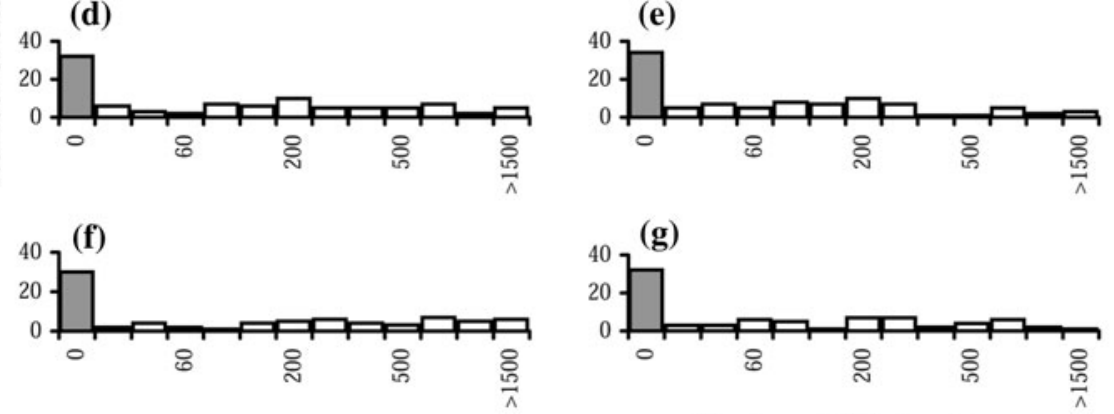

Number of fish at a site

Fig. 2 Frequency (number of sites) of the number of fish life histories captured at a site in western Iberia: (a) juvenile Barbus bocagei; (b) small adult Barbus bocagei; (c) large adult Barbus bocagei; (d) juvenile Pseudochondrostoma duriense; (e) adult

gradients as independent variables. An information-theoretic approach - the Bayesian Information Criterion (BIC; Schwarz 1978) — was used as a model selection procedure, in which the best-fitting partial model is that with the lowest BIC value. Though BIC is less used than AIC (Akaike Information Criterion, Burnham and Anderson 2002) in ecological studies, it provides more consistent model selection estimates than the latter (see for example Claeskens and Hjort 2008). In addition BIC also produces more parsimonious (Barbottin et al. 2010) and precise (Alfaro and Huelsenbeck 2006) models than AIC. Therefore, given the present complex model framework, multivariate modelling based on the philosophy of model based inference seemed more adequate and ecologically meaningful with BIC rather than with AIC. The BIC permits the simultaneous comparison of multiple models in such a way as to select the most parsimonious model consistent with the data, while balancing precision and bias (Franklin et al. 2000). The BIC values were adjusted for bias due to small sample size $\left(\mathrm{BIC}_{\mathrm{c}}\right)$, and the difference between each $\mathrm{BIC}_{\mathrm{c}}$ value and the $\mathrm{BIC}_{\mathrm{c}}$ of the top-ranked model $\left(\Delta_{i}\right)$ was calculated. This BIC difference estimates the fit of each model compared to that of the best-fitting model. Models presenting $\Delta_{i} \leq 2$ are typically considered to have substantial support, and should be considered along with the best model (Burnham and Anderson 2002). The model ranking was then inspected to determine whether more than one model had substantial support (none had). For the resulting set of models, in order to evaluate model plausibility, the BIC weights $\left(w_{i}\right)$, which represent the relative likelihood of each model given the data, were calculated as the ratio of the likelihood of each model to
Pseudochondrostoma duriense; (f) juvenile Pseudochondrostoma polylepis and (g) adult Pseudochondrostoma polylepis. Note that over $35 \%$ of each dataset is represented by zero counts

the sum of all the model likelihoods. Thus the model with the lowest $\mathrm{BIC}_{\mathrm{c}}$ and consequently the highest $w_{i}$ was considered the best model. The significant environmental gradients of the best partial model (i.e. regional and local) were then retained to produce a final global model for each species life stage.

Lastly, to assess the relative importance of regional and local gradients in the selected models, variation partitioning was used to decompose the variation explained by the best models into four different components. The methodology followed is an adaptation of that developed by Borcard et al. (1992) and Legendre and Legendre (1998), but extended here to hurdle models by using Nagelkerke pseudo- $R^{2}$ values (Nagelkerke 1991), instead of $R^{2}$, in order to have an approximate measure of the variation. For each species life stage the best candidate model was considered-i.e. the model with the lowest $\mathrm{BIC}_{\mathrm{c}}$ value. First, a "partial" hurdle model was fitted with only the regional subset of predictors present in the best candidate model (yielding the quantity $a+b$ ). The same procedure was then performed with the difference that a second "partial" model was only fitted with the local subset of predictors (yielding $b+c$ ). Finally, the "full" model (with all the predictors) was fitted to obtain the shared effects $(a+b+c)$ (see Reino 2005; Morgado et al. 2010). Following this analysis, the total variation explained by each species life stage model $\left(\mathrm{V}=\sum a+b+c+d\right)$ was partitioned into four independent components: (i) a pure regional component (a), not explained by the local component; (ii) a shared component, i.e., the regional variation that is locally and spatially structured (b); (iii) a pure local component (c), independent of the regional variables, and; 
(iv) any unexplained variation not attributed to any component (d). PCA were carried out with the Statistica program (StatSoft Inc. 2000). Hurdle models were fitted in the R 2.7.2 (R Development Core Team 2008) software using the hurdle function of the PSCL package (Zeileis et al. 2008).

\section{Results}

Fish species

Species counts ranged from 0 to 7900 individuals, depending on life stages present at a given site (Table 2). Strong evidence of overdispersion was also found for all species life-stages, as the variance was much greater than the mean of the data.

\section{Environmental gradients}

Principal component analyses performed on large-scale regional variables for each species area of occurrence, yielded three components with eigenvalues $>1$, which accounted for between $80.4 \%$ ( $P$. duriense) and $82.1 \%$ ( $P$. polylepis) of the total variation. The variables retained (i.e. with loadings $\geq|0.70|$ ) in each component were similar, in terms of magnitude and direction, for the three species considered. Principal component 1 (regional gradient $1, \mathrm{PC}_{\mathrm{R} 1}$ ) was positively loaded on gradient slope (SLO) and negatively loaded on catchment area (CAREA) and distance from source (DSOUR), and therefore described a longitudinal gradient towards upstream steeper river sites (Table 3). $\mathrm{PC}_{\mathrm{R} 2}$ was flow-related with high negative loadings on mean annual rainfall (RAIN) and average annual runoff (ROFF), and therefore described a gradient from higher rainfall areas towards sites with lower

Table 2 Mean, variance, maximum (Max) and minimum (Min) values of counts (number of fish/ha) for the seven species life stages collected at 174 sites in western Iberia

\begin{tabular}{lcccc}
\hline Species & Mean & Variance & Max & Min \\
\hline Barbus bocagei & (Steidachner) & & & \\
Juvenile & 359.3 & $7.97 \times 10^{5}$ & 6400 & 0 \\
Small adult & 262.5 & $2.15 \times 10^{5}$ & 3400 & 0 \\
Large adult & 51.5 & $2.36 \times 10^{4}$ & 1700 & 0 \\
\multicolumn{2}{l}{ Pseudochondrostoma duriense } & (Coelho) & & \\
Juvenile & 263.5 & $2.22 \times 10^{5}$ & 2200 & 0 \\
Adult & 181.5 & $1.54 \times 10^{5}$ & 2100 & 0 \\
Pseudochondrostoma polylepis & $($ Steidachner) & & \\
Juvenile & 467.4 & $1.18 \times 10^{6}$ & 7900 & 0 \\
Adult & 192.8 & $1.08 \times 10^{5}$ & 1550 & 0 \\
\hline
\end{tabular}

precipitation and runoff. Altitude (ALT) was positively loaded and mean air temperature (ATEMP) and mineralization (MIN) were negatively loaded on $\mathrm{PC}_{\mathrm{R} 3}$. This gradient largely reflected a shift towards colder and lowmineralised water rivers.

Similarly, PCAs on instream local variables recorded for each species area of occurrence generated three components with eigenvalues $>1$, which accounted for between $66.0 \%$ (P. polylepis) and $80.5 \%$ (P. duriense) of the total variation. Again, selected variables in each component were numerically similar for the three species considered. $\mathrm{PC}_{\mathrm{L} 1}$ (local gradient 1) was a habitat-size gradient with high loadings on mean width (MWID) and mean depth (MDEP), and was inversely related with instream shade (SHAD), thus representing larger and deeper sites with high canopy openness. $\mathrm{PC}_{\mathrm{L} 2}$ loaded high on instream cover (COV) and substrate coarseness (SUBS), thus reflecting sites with coarser substrates and higher instream cover. The final local gradient extracted $\left(\mathrm{PC}_{\mathrm{L} 3}\right)$ was positively related with water velocity (WVEL), thus representing fast-flowing sites.

Multi-scale effects on species life stage occurrence and counts

The hurdle models showed that occurrence and counts of species life stages were significantly related with both regional and local gradients. Table 4 shows the top-ranked "partial" models for each species life stage, as no other models showing substantial support $(\Delta i \leq 2)$ were found. Model selection results also suggested a relatively low to moderate plausibility for each of the best ranking models in terms of $\mathrm{BIC}_{\mathrm{c}}\left(0.26 \leq w_{i} \leq 0.58\right.$ and $0.29 \leq w_{i} \leq 0.61$, for regional and local models respectively) (Table 4). Results also showed some differences in model plausibility when considering different species or life-stages. Model selection plausibility for regional models was slightly higher for juvenile B. bocagei and P. polylepis. On the other hand, model selection plausibility for adult $P$. duriense was higher than for juveniles (Table 4). Local models showed that model selection plausibility was higher for small adults and adults for $B$. bocagei and $P$. polylepis respectively, whereas in the case of $P$. duriense, juveniles had higher model selection plausibility (Table 4).

$\mathrm{PC}_{\mathrm{R} 1}$ underlined a strong tendency for B. bocagei and adult Pseudochondrostoma spp. to occupy low-gradient river reaches, with higher catchment areas and located farthest from sources. Counts of adults of the former species displayed a similar spatial distribution. On the contrary, juvenile $P$. duriense showed a positive association with high-gradient upstream rivers. A flow-related gradient $\left(\mathrm{PC}_{\mathrm{R} 2}\right)$ was found to be inversely associated with the occurrence of juvenile $P$. duriense, whereas both adult B. bocagei and Pseudochondrostoma were positively 
Table 3 Loadings of regional and local variables on the first three principal components (PC) extracted by PCA and the eigenvalues and proportions of variance accounted for by each axis for the 174 sites sampled in western Iberia

\begin{tabular}{|c|c|c|c|c|c|c|c|}
\hline \multirow[t]{2}{*}{ Regional variables } & \multicolumn{3}{|c|}{$\mathrm{PC}_{\mathrm{R}}$ axes } & \multirow[t]{2}{*}{ Local variables } & \multicolumn{3}{|c|}{$\mathrm{PC}_{\mathrm{L}}$ axes } \\
\hline & 1 & 2 & 3 & & 1 & 2 & 3 \\
\hline Catchment area & -0.95 & & & Mean width & 0.82 & & \\
\hline Distance from source & -0.95 & & & Shade & -0.74 & & \\
\hline Gradient slope & 0.80 & & & Mean depth & 0.71 & & \\
\hline Mean annual rainfall & & -0.94 & & Substrate coarseness & & 0.89 & \\
\hline Average annual runoff & & -0.94 & & Cover & & 0.76 & \\
\hline Altitude & & & 0.92 & Water velocity & & & 0.86 \\
\hline Mean air temperature & & & -0.83 & & & & \\
\hline Mineralisation & & & -0.71 & & & & \\
\hline Eigenvalue & 2.7 & 2.3 & 1.5 & Eigenvalue & 2.5 & 1.3 & 1.2 \\
\hline Variance $(\%)$ & 34.0 & 28.3 & 19.3 & Variance $(\%)$ & 35.0 & 18.2 & 17.0 \\
\hline
\end{tabular}

Marked loadings are $>|0.70|$

Table 4 Summary results of model selection for the relationships between species life-history stages and environmental gradients reflected in each of the three components $\left(\mathrm{PC}_{\mathrm{n}}\right)$ extracted from principal component analyses of regional $(\mathrm{R})$ and local $(\mathrm{L})$ variables

\begin{tabular}{|c|c|c|c|c|c|c|c|c|c|c|c|c|c|c|}
\hline \multirow[t]{3}{*}{ Species } & \multicolumn{7}{|c|}{ Regional models } & \multicolumn{7}{|c|}{ Local models } \\
\hline & \multirow[t]{2}{*}{$w_{i}$} & \multicolumn{3}{|c|}{ Pres/abs } & \multicolumn{3}{|l|}{ Count } & \multirow[t]{2}{*}{$w_{i}$} & \multicolumn{3}{|c|}{ Pres/abs } & \multicolumn{3}{|c|}{ Count } \\
\hline & & $\mathrm{PC}_{\mathrm{R} 1}$ & $\mathrm{PC}_{\mathrm{R} 2}$ & $\mathrm{PC}_{\mathrm{R} 3}$ & $\mathrm{PC}_{\mathrm{R} 1}$ & $\mathrm{PC}_{\mathrm{R} 2}$ & $\mathrm{PC}_{\mathrm{R} 3}$ & & $\mathrm{PC}_{\mathrm{L} 1}$ & $\mathrm{PC}_{\mathrm{L} 2}$ & $\mathrm{PC}_{\mathrm{L} 3}$ & $\mathrm{PC}_{\mathrm{L} 1}$ & $\mathrm{PC}_{\mathrm{L} 2}$ & $\mathrm{PC}_{\mathrm{L} 3}$ \\
\hline \multicolumn{15}{|l|}{ B. bocagei } \\
\hline Juvenile & 0.58 & -0.81 & & 0.80 & & & 0.55 & 0.43 & -1.50 & & -0.67 & & 0.28 & \\
\hline Small adult & 0.47 & -1.15 & 0.45 & & -0.28 & & & 0.61 & -1.17 & & & & & \\
\hline Large adult & 0.53 & -1.61 & 0.57 & & -0.37 & 0.44 & & 0.38 & 0.83 & & & & & \\
\hline \multicolumn{15}{|l|}{ P. polylepis } \\
\hline Juvenile & 0.47 & & & 0.77 & & & & 0.29 & & & & & 0.52 & 0.54 \\
\hline Adult & 0.37 & -0.66 & 0.70 & & & & & 0.51 & 1.30 & & & & -0.55 & \\
\hline \multicolumn{15}{|l|}{ P. duriense } \\
\hline Juvenile & 0.26 & 0.98 & -1.08 & & & & & 0.49 & & & & & 0.36 & 0.57 \\
\hline Adult & 0.33 & -0.51 & 0.31 & & & & & 0.33 & 0.71 & & & 0.69 & & \\
\hline
\end{tabular}

For each response variable, the table provides the Akaike weights $\left(w_{i}\right)$ of the best fitting partial model and the regression coefficient of each principal component. Gradients in bold were included $(p<0.05)$ in the final global model

related with this regional gradient-i.e. occupied drier and lower runoff areas. The presence and counts of juvenile $B$. bocagei and $P$. polylepis was found to be related with colder altitudinal sites presenting low-mineralization waters, as shown by a positive association with $\mathrm{PC}_{\mathrm{R} 3}$.

Local gradients were also significant correlates for the occurrence and counts of the different species life-stages. Accordingly, the habitat size gradient $\mathrm{PC}_{\mathrm{L} 1}$ displayed a positive effect on the occurrence of large adult $B$. bocage $i$ and on the adults from both Pseudochondrostoma species, as they were mainly found at wider and deeper sites. On the other hand, juvenile B. bocagei displayed a negative association with such areas. Sites presenting higher instream cover and substrate coarseness, as shown by $\mathrm{PC}_{\mathrm{L} 2}$, favoured the counts of juvenile $B$. bocagei and juvenile
Pseudochondrostoma. The latter were also associated with fast-flowing areas-i.e. higher and medium courses of rivers-inasmuch as their count was found to show a positive effect with $\mathrm{PC}_{\mathrm{L} 3}$.

Variation partitioning for hurdle models

Regional, local and shared components managed to explain between $11.3 \%$ (juvenile $P$. polylepis) and $43.5 \%$ (adult $P$. polylepis) of model variation, but the source of distribution patterns varied according to the species life stage considered (Fig. 3). "Pure" regional attributes represented a higher portion of variation, compared to "pure" local components in all life stages of B. bocagei, particularly large adults, which ranged from 38.49 to $46.61 \%$. In 


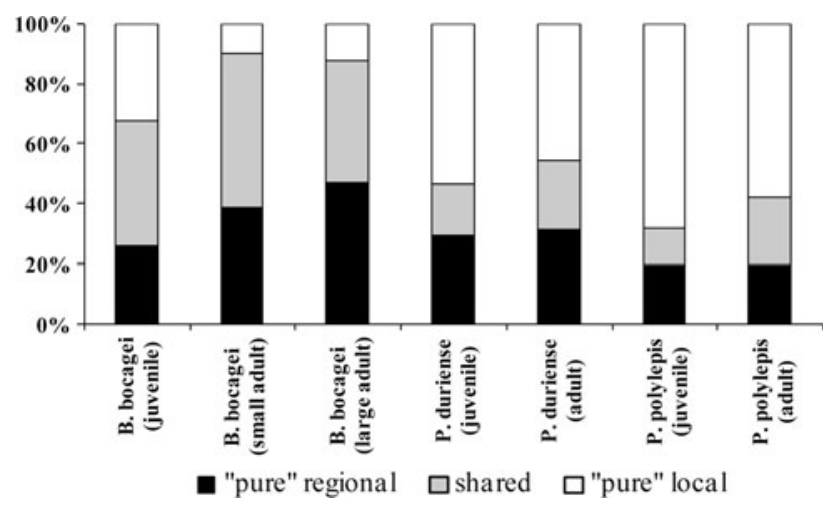

Fig. 3 Explained variation partitioning ("pure" regional, shared and "pure" local variation) applied to the hurdle models developed for each species life stage in western Iberia

contrast, after accounting for regional components, "pure" local gradients were highly represented in life stages of both nase, especially juveniles, ranging from $45.82 \%$ (adult $P$. duriense) to $68.23 \%$ (juvenile $P$. polylepis), thus suggesting an underlying reach-scale spatial trend in their distribution. The shared effects, which represented the amount of variation that could be explained by the overlap between landscape-scale descriptors (i.e. regional factors) and local attributes, ranged from $12.26 \%$ (juvenile $P$. polylepis) to $51.62 \%$ (small adult B. bocagei).

\section{Discussion}

The present study focused on the influence of both regional and local attributes on the distribution of different life stages of native Iberian cyprinid fishes, and in doing so emphasized the need to use this kind of multi-scale approach in order to understand the hierarchical patterns of species spatial organisation. It also differed from many others in that it was performed at a network of minimally disturbed sites, and thus represented a true and accurate picture of the reality and not a consequence of any humanimposed displacement towards sub-optimal conditions (see Ferreira et al. 2007a).

Incorrect model specification can have substantial impacts on model prediction and may lead to erroneous conclusions that then affect decision-making by environmental managers (Potts and Elith 2006). Because the present datasets were found to be zero-inflated and overdispersed, the hurdle model was used rather than the more common and straightforward Poisson model, to correctly deal with the problem of excess zeros that is frequently encountered in many ecological datasets (Martin et al. 2005). The use of these models provided support for the basic hypothesis of our modelling approach: that significant relationships exist between species life stage occurrence and counts and landscape influences at multiple (i.e. regional and local) spatial scales. However, there may have been other factors which were not accounted for in the present analyses and which might increase predictive power. For example, dissolved oxygen, $\mathrm{pH}$, and conductivity, which are often considered in model prediction studies at a local scale (Bain and Robinson 1988; Fausch et al. 1988), could also have been important in this study. Biotic interactions, such as competition and predation, which are inherently local in scale, are likely to affect local species counts and distribution. However, given the broad extent of this study, their contribution to the generation of the observed patterns is unlikely to be significant, as the importance of biotic factors is thought to decrease with increases in spatial scale (Tonn et al. 1990).

The selected models clearly outlined the importance of examining species life stage-environmental gradient relationships at different spatial scales (regional and local), and showed that distribution patterns contrasted depending on life stage. Although in general all barbel life stages were associated with downstream low-gradient river reaches, this pattern was more pronounced at advanced stages (large adults), as shown by the lower regression coefficients on regional gradient 1 - the longitudinal river gradient. This is also supported by a positive association of juveniles with colder (upstream) sites. On the other hand, a life-stage spatial segregation-i.e. adults showing negative associations with high-order streams, whereas juveniles favoured such areas-was noted for nases. Although the association of all barbel stages with mid- and lower river courses was to be expected (Santos et al. 2004), the results also provided new insights into the presence of both nase life stages along a longitudinal gradient. Indeed, juvenile nases were found to occupy steeper fast-flowing headwater river reaches, which is not in accordance with the existing literature in which individuals of this species are reported to inhabit mid-lower river courses (Carmona et al. 1999; Santos et al. 2005; Ferreira et al. 2007a). This highlights the need to consider the use of different life stages when making spatial distribution assessments that are particularly important from a conservation point of view. Though the large-scale gradient of longitudinal position has been shown to influence fish distribution within river systems elsewhere (Joy and Death 2002; Mugodo et al. 2006), other factors were also important in shaping the spatial organisation of species life stages.

Physical habitat and channel morphology descriptors also played an important role in species occurrence and counts. Stream width and openness were negatively related with the presence of juvenile and small adult barbel, whereas large adults were mainly found in wider and deeper rivers. Similar findings (i.e. larger fish associated with wider river sections) have been outlined in the 
literature (Pires et al. 1999; Morán-López et al. 2006), and emphasize the importance of width as an indicator of complexity and stability in structuring stream fish distribution (Gorman and Karr 1978; Schlosser 1995). In addition to width, canopy openness also loaded high on the first local gradient extracted by PCA, and showed a positive association with large adult barbel. In contrast, smaller-sized individuals were found to favour areas with low canopy openness-i.e. those presenting a high shade cover. The importance of shade to fishes-in particular small-sized classes-has been demonstrated in a number of papers, in that it provides refuge from predators, mainly in upper reaches and smaller tributaries (Schiemer et al. 1995; Stauffer et al. 2000). The association of shade with stream width is also known to influence water temperature and therefore metabolic rates, which control growth and determine population size (Jobling 1995), as increased width-to-depth ratio and decreased shade lead to an increase in mean water temperature (Pusey and Arthington 2003). Substrate coarseness and cover were also important correlates of species life stages distribution, as shown by significant associations with the second local PCA component. Accordingly, both variables were positively related with the counts of juveniles of the target species. It is hypothesized that juveniles used high-covered gravel-pebble areas as nurseries in upstream reaches, because of their shoreline structure, high retention of organic material, and stable temperature regimes. Similar findings have been found for other lithophilic barbel and nase in Central Europe (Jurajda 1999; Schiemer et al. 2003), and highlight the need to identify and protect such areas in order to maintain fish populations in Iberian streams. Taken as a whole, the observed patterns are consistent with the general theoretical expectation that considerable complementarity exists in the spatial distribution of life stages along a longitudinal gradient (Schlosser 1995; Fausch et al. 2002). Earlier life stages tended to be found predominantly in upstream higher-gradient river reaches, while later stages were mainly associated with lower and wider slow-flowing river sections (Schlosser 1987; Lobb and Orth 1991). Consequently, this study recognized the need to consider landscape heterogeneity at multiple spatial scales as a fundamental factor among the influences on the distribution of species life stages in Iberian rivers.

Both regional and local descriptors were important correlates of species life stages distribution in western Iberia. The purely local attributes accounted for much of the model variation of both nase, and the juveniles in particular. Previous studies had pointed out the role of physical factors and hydraulic conditions, such as substrate and velocity, in governing the distribution of nase (Santos et al. 2006; Ferreira et al. 2007a). In the present study the contribution of such factors seemed to be greater in early stages (juveniles), as can also be seen from the significant positive associations with such variables, thereby highlighting their importance to the satisfaction of critical life stage requirements. Moreover, given that habitat attributes are in turn likely to be influenced by physical processes operating at larger spatial scales (Frissell et al. 1986; Mugodo et al. 2006), it is possible that a part of the high local variation observed may implicitly have a regional structure. For example, variables linked to river morphology (e.g. substrate coarseness and velocity) may have a longitudinal component, as rivers in the study area flow mostly in the same westward direction, so their effect could be countered by the effect of geography. The higher dependence of juveniles on local-scale factors could also be related with other factors, such as regional dispersal to and from connected rivers. Hitt and Angermeier (2008) found that by regulating fish dispersal, river connectivity to riverine areas affects the relative importance of regional and local factors in shaping the distribution of stream fishes. Accordingly, the observed patterns could also reflect a restriction on the capacity of juvenile nases to explore nearby connected streams, thus suggesting that in highgradient headwater rivers, these fishes are more limited by local-scale factors than adults inhabiting downstream lower-gradient river reaches farther from sources, due to the latter's opportunistic use of connected riverine habitats. The use of advancing techniques such as radio-telemetry may help to elucidate species life stage occupancy and the movements of individuals and their use of particular habitats. Such technology may provide the basis for determining detailed information about small-scale environmental conditions and larger-scale use of streams.

On the other hand, factors related with large-scale geography possessed a greater explanatory capacity in relation to the species (barbel) that occupied the largest streams, and particularly adults. Although the dominance of larger individuals in larger lowland habitats is a common occurrence in many Iberian rivers (Godinho et al. 2000; Santos et al. 2004), the relatively small influence of local factors on adult barbel distribution found in the present study may reflect the very large geographic scale—all eight river catchments-in which they were collected (Roth et al. 1996; Marsh-Matthews and Matthews 2000). Unlike adult barbel, which are known to undertake considerable upstream movements within rivers in order to spawn (Santos et al. 2005), the purely local attributes accounted for much of the model variation in the juvenile barbel. Taken together, these results suggest that potamodromous adult barbel, whose spatial distribution is mainly driven by regional attributes, have traits that allow them to pass through habitat filters at the stream and reach scale (sensu Frissell et al. 1986, Dollar et al. 2006), in order to complete their life cycle. These filters determine the spatial dynamics 
of their progeny (i.e. juveniles) at the reach scale, and their count is then primarily affected by local habitat. The findings of this study therefore point to the need to account for the use of different life stages when modelling the influence of landscape attributes on fish populations at multiple spatial scales. It is true that the explanatory gradients together explained from 11.3 to $43.5 \%$ of the total variability, but this left a fairly high portion unexplained. This implies that fish life-stage occurrence and counts may vary over space and time in response to other environmental or biological mechanisms that were not accounted for in the present study (biotic interactions, food abundance, and recruitment effects), and makes it necessary to look in more depth at their role in governing the spatial distribution of species life stages.

Results of the present study showed that the occurrence and counts of cyprinids at different spatial scales was strongly dependent on the life stages of individuals. Juveniles, which primarily responded to local factors, may be more vulnerable to immediate disturbances, such as barrier construction, that restrain their distribution in upstream river reaches. Monitoring juveniles would surely provide sound information on current stock trends and/or habitat changes, and this suggests that their spatial distribution would be a good bioindicator of river connectivity and stock status. Maintaining connectivity and local habitat quality is therefore extremely important for supporting their populations. The use of juveniles as "functional describers" would therefore provide fisheries managers with a cost-effective method with which to assess and predict a river function in terms of fish reproduction and recruitment. As fish reproduction is strongly influenced by environmental conditions, the impact of natural or human disturbances could be assessed by sampling juvenile populations. Moreover, the latter's monitoring generally requires relatively little effort in the field, as they are relatively easy to identify and count. On the other hand, advanced life stages, such as those of adult barbel, which primarily responded to regional gradients, are likely to be mainly affected by large-scale disturbances, such as climate change and land-use modifications, and can be therefore less responsive to local management actions (Ferreira et al. 2007a). However, the results of this study should be viewed with caution, as they represent an ecological snapshot, and populations of stream fishes generally undertake important aspects (e.g. reproduction, growth, shelter) of their entire life histories at different periods (Fausch et al. 2002; Pollux et al. 2006). Temporal variation, which could not be detected by our single sampling at each site, may play a major role in understanding the importance of the spatial distribution of species life stages. Future studies should consider monitoring fish populations at appropriate temporal scales, in such a way as to record life-history events and important physical disturbances that would certainly provide additional insights for understanding the environmental correlates of potamodromous Iberian species and their implication for species management and conservation.

Acknowledgments The authors would like to thank Luis Lopes, António Albuquerque and Rui Rivaes for help with the field work. We are also grateful to Achim Zeileis from WU Wirtschaftsuniversität Wien for his help with the hurdle models under the PSCL package. Finally, the authors would like to thank two anonymous reviewers would greatly improved an early draft of this paper. José Maria Santos was supported by a grant from the Foundation for Science and Technology (FCT) (SFRH/BPD/26417/2006); Luis Reino was funded by the FCT grants SFRH/BD/14085/2003 and SFRH/BPD/62865/ 2009, and Miguel Porto was funded by the FCT PhD grant SFRH/BD/ $28974 / 2006$.

\section{References}

Agência Portuguesa do Ambiente (2007) Atlas do Ambiente Digital. http://www.iambiente.pt/atlas/est/index.jsp. Accessed 24 June 2008

Alfaro ME, Huelsenbeck JP (2006) Comparative performance of Bayesian and AIC-based measures of phylogenetic model uncertainty. Syst Biol 55:89-96

Allan JD (2004) Landscapes and riverscapes: the influence of land use on stream ecosystems. Annu Rev Ecol Syst 35:257-284

Allan JD, Erickson DL, Fay J (1997) The influence of catchment land use on stream integrity across multiple spatial scales. Freshw Biol 37:149-161

Bain MB, Robinson CL (1988) Structure, performance, and assumptions of riverine habitat suitability index models. Aquatic Resources Research Series 88-3, Alabama Cooperative Fish and Wildlife Research Unit. Auburn University, Auburn

Barbottin A, Tichit M, Cadet C, Makowski D (2010) Accuracy and cost of models predicting bird distribution in agricultural grasslands. Agr Ecosyst Environ 136:28-34

Borcard D, Legendre P, Drapeau P (1992) Partialling out the spatial component of ecological variation. Ecology 73:1045-1055

Burnham KP, Anderson DR (2002) Model selection and multimodel inference: a practical information-theoretic approach. Springer, New York

Carmona JA, Doadrio I, Márquez AL, Real R, Hugueny B, Vargas JM (1999) Distribution patterns of indigenous freshwater fishes in the Tagus River basin, Spain. Environ Biol Fish 54:371387

CEN (Comité Européen de Normaliation) (2003) Water quality: sampling of fish with electricity. CEN, European Standard EN 14011. European Committee for Standardization, Brussels

Claeskens G, Hjort NL (2008) Model selection and model averaging. Cambridge University Press, Cambridge

Copp GH (1989) Electrofishing for fish larvae and $0+$ juveniles: equipment modifications for increased efficiency with short fishes. Aquac Res 20:453-462

Cragg JG (1971) Some statistical models for limited dependent variables with application to the demand for durable goods. Econometrica 39:829-844

Doadrio I (2001) Atlas y Libro Rojo de los Peces Continentales de España. Ministerio de Medio Ambiente, Madrid

Dollar ESJ, James CS, Rogers KH, Thoms MC (2006) A framework for interdisciplinary understanding of rivers as ecosystems. Geomorphology 89:147-162 
Fausch KD, Hawkes CL, Parsons MG (1988) Models that predict standing crop of stream fish from habitat variables: 1950-85. General Technical Report PNW-GTR-213. US Department of Agriculture, Forest Service, Pacific Northwest Research Station, Portland, OR, p 52

Fausch KD, Torgersen CE, Baxter CV, Li HW (2002) Landscapes to riverscapes: bridging the gap between research and conservation of stream fishes. Bioscience 52:483-498

Ferreira MT, Caiola N, Casals F, Oliveira J, Soatoa A (2007a) Assessing perturbation of river fish communities in the Iberian ecoregion. Fish Manag Ecol 14:519-530

Ferreira MT, Sousa L, Santos JM, Reino L, Oliveira J, Almeida PR, Cortes RV (2007b) Regional and local environmental correlates of native Iberian fish fauna. Ecol Freshw Fish 16:504-514

Franklin AB, Anderson DR, Gutierrez RJ, Burnham KP (2000) Climate, habitat quality, and fitness in northern spotted owl populations in northwestern California. Ecol Monogr 70: 539-590

Frissell CA, Liss WJ, Warren CE, Hurley MD (1986) A hierarchical framework for stream habitat classification: viewing streams in a watershed context. Environ Manage 10:199-214

Godinho FN, Ferreira MT, Santos JM (2000) Variation in fish community composition along an Iberian river basin from low to high discharge: relative contributions of environmental and temporal variables. Ecol Freshw Fish 9:22-29

Gorman OT, Karr JR (1978) Habitat structure and stream fish communities. Ecology 59:507-515

Hitt NP, Angermeier PL (2008) River-stream connectivity affects fish bioassessment performance. Environ Manage 42:132-150

Huston MA (1999) Local processes and regional patterns: appropriate scales for understanding variation in the diversity of plants and animals. Oikos 86:393-401

Jobling M (1995) Environmental biology of fishes. Chapman and Hall, London

Joy MK, Death RG (2002) Predictive modelling of freshwater fish as a biomonitoring tool in New Zealand. Freshw Biol 47:2261-2275

Jurajda P (1999) Comparative nursery habitat use by $0+$ fish in a modified lowland river. Regul River 15:113-124

Lammert M, Allan JD (1999) Assessing biotic integrity of streams: effects of scale in measuring the influence of land use/cover on habitat structure on fish and macroinvertebrates. Environ Manage 23:257-270

Legendre P, Legendre L (1998) Numerical ecology. Elsevier Science, Amsterdam

Lobb DM, Orth DJ (1991) Habitat use by an assemblage of fish in a large warmwater stream. Trans Am Fish Soc 120:65-78

Lobón-Cerviá J (1982) Population analysis of the Iberian nose (Chondrostoma polylepis Stein, 1865) in the Jarama river. Vie Milieu 32:139-148

Lobón-Cerviá J, Fernandez-Delgado C (1984) On the biology of the barbel (Barbus barbus bocagei) in the Jarama river. Folia Zool 33:371-384

Lucas MC, Baras E (2001) Migration of freshwater fishes. Blackwell Science, Oxford

Marsh-Matthews E, Matthews WJ (2000) Geographic, terrestrial and aquatic factors: which most influence the structure of stream fish assemblages in the Midwestern United States. Ecol Freshw Fish 9:9-21

Martin TG, Wintle BA, Rhodes JR, Kuhnert PM, Field SA, LowChoy SJ, Tyre A, Possimgham HP (2005) Zero tolerance ecology: improving ecological inference by modelling the source of zero observations. Ecol Lett 8:1235-1246

Melcher A, Schmutz S, Haidvogl G, Moder K (2007) Spatially based methods to assess ecological status of European fish assemblage types. Fisheries Manag Ecol 14:453-463
Mesquita N, Coelho MM, Magalhães MT (2006) Spatial variation in fish assemblages across small Mediterranean drainages: effects of habitat and landscape context. Environ Biol Fish 77:105-120

Morán-López R, Da Silva E, Pérez-Bote JL, Amado CC (2006) Associations between fish assemblages and environmental factors for Mediterranean-type rivers during summer. J Fish Biol 69:1552-1569

Morgado R, Beja P, Reino L, Gordinho L, Delgado A, Borralho R, Moreira F (2010) Calandra lark habitat selection: strong fragmentation effects in a grassland specialist. Acta Oecol 36:63-73

Mugodo J, Kennard M, Liston P, Nichols S, Linke S, Norris RH, Lintermans M (2006) Local stream habitat variables predicted from catchment scale characteristics are useful for predicting fish distribution. Hydrobiologia 572:59-70

Nagelkerke NJD (1991) A note on a general definition of the coefficient of determination. Biometrika 78:691-692

Northcote TG (1978) Migratory strategies and production in freshwater fishes. In: Gerking SD (ed) Ecology of freshwater fish production. Blackwell, Oxford, pp 329-359

Olden JD, Jackson DA (2002) A comparison of statistical approaches for modelling fish species distributions. Freshw Biol 47:1976-1995

Oliveira JM (2006) Biotic integrity of Iberian rivers based on fish assemblages. PhD Dissertation, Superior Agronomy Institute

Oliveira JM, Ferreira AP, Ferreira MT (2002) Intrabasin variations in age and growth of Barbus bocagei populations. J Appl Ichthyol 18:134-139

Ostrand KG, Wilde GR (2002) Seasonal and spatial variation in a prairie stream-fish assemblage. Ecol Freshw Fish 11:137-149

Pires AM, Cowx IG, Coelho MM (1999) Seasonal changes in fish community structure of intermittent streams in the middle reaches of the Guadiana basin, Portugal. J Fish Biol 54:235-249

Podlich HM, Faddy MJ, Smyth GK (2002) A general approach to modeling and analysis of species abundance data with extra zeros. J Agric Biol Environ S 7:324-334

Pollux BJ, Korosi A, Verberk WC, Pollux PM, Velde VD (2006) Reproduction, growth, and migration of fishes in a regulated lowland tributary: potential recruitment to the river Meuse. Hydrobiologia 565:105-120

Pont T, Hugueny B, Oberdorff T (2005) Modelling habitat requirement of European fishes: do species have similar responses to local and environmental constrains? Can J Fish Aquat Sci 62:163-173

Pont D, Hugueny B, Rogers C (2007) Development of a fish-based index for the assessment of river health in Europe: the European Fish Index. Fish Manag Ecol 14:427-439

Potts J, Elith J (2006) Comparing species abundance models. Ecol Model 199:153-163

Pusey BJ, Arthington AH (2003) Importance of the riparian zone to the conservation and management of freshwater fish: a review. Mar Freshw Res 54:1-16

R Development Core Team (2008) R: a language and environment for statistical computing. R Foundation for Statistical Computing, Vienna, Austria. http://www.r-project.org

Reino L (2005) Variation partitioning for range expansion of an introduced species: the common waxbill Estrilda astrild in Portugal. J Ornithol 146:377-382

Reino L, Beja P, Heitor AC (2006) Modelling spatial and environmental effects at the edge of the distribution: the red-backed shrike Lanius collurio in Northern Portugal. Divers Distrib 12:379-387

Ridout M, Demetrio C, Hinde J (1998) Models for count data with many zeros. In: Proceedings of the 19th international biometric conference, Cape Town, pp 179-192

Root TL, Schneider SH (1995) Ecology and climate: research strategies and implications. Science 269:334-341 
Roth NE, Allan JD, Erickson DL (1996) Landscape influences on stream biotic integrity assessed at multiple spatial scales. Landsc Ecol 11:141-156

Santos JM, Godinho FN, Ferreira MT, Cortes RV (2004) The organisation of fish assemblages in the regulated Lima basin, Northern Portugal. Limnologica 34:224-235

Santos JM, Ferreira MT, Godinho FN, Bochechas J (2005) Efficacy of a nature-like bypass channel in a Portuguese lowland river. J Appl Ichthyol 21:381-388

Santos JM, Ferreira MT, Pinheiro AN, Bochechas J (2006) Effects of small hydropower plants on fish assemblages in medium-sized streams in Central and Northern Portugal. Aquat Conserv 16:373-388

Schiemer F, Zalewski M, Thorpe J (1995) Land/inland water ecotones: intermediate habitats critical for conservation and management. Hydrobiologia 303:259-264

Schiemer F, Keckeis H, Kamler E (2003) The early life history stages of riverine fish: ecophysiological and environmental bottlenecks. Comp Biochem Phys A 133:439-449

Schlosser IJ (1987) The role of predation in age and size related habitat use by stream fishes. Ecology 68:651-659

Schlosser IJ (1991) Stream fish ecology: a landscape perspective. Bioscience 41:704-712

Schlosser IJ (1995) Critical landscape attributes that influence fish population dynamics in headwater streams. Hydrobiologia 303:71-81
Schwarz G (1978) Estimating the dimension of a model. Ann Stat 6:461-464

StatSoft, Inc (2000) STATISTICA for Windows (computer program manual). StatSoft, Tulsa Oklahoma

Stauffer JC, Goldstein RM, Newman RM (2000) Relationship of wooded riparian zones and runoff potential to fish community composition in agricultural stream. Can J Fish Aquat Sci 57:307-316

Tonn WM, Magnuson JJ, Rask M, Toivonen J (1990) Intercontinental comparison of small-lake fish assemblages: the balance between local and regional processes. Am Nat 136:345-375

Tyre AJ, Tenhumberg B, Field SA, Niejalke D, Parris K, Possingham HP (2003) Improving precision and reducing bias in biological surveys: estimating false negative error rates. Ecol Appl 13: 1790-1801

Welsh AH, Cunningham RB, Chambers RL (2000) Methodology for estimating the abundance of rare animals: seabird nesting on north east Herald Cay. Biometrics 56:22-30

Wiley MJ, Kohler SL, Seelbach PW (1997) Reconciling landscape and local views of aquatic communities: lessons from Michigan trout streams. Freshwater Biol 37:133-148

Zeileis A, Kleiber C, Jackman S (2008) Regression models for count data in R. J Stat Softw 27(8):1-25 